\title{
Interstitial lung fluid balance in healthy lowlanders exposed to high-altitude
}

\section{Short Title}

Lung fluid balance at high-altitude

\section{Authors}

Bryan J. Taylor ${ }^{1,2}$, Glenn M. Stewart ${ }^{2}$, Jan W. Marck ${ }^{2}$, Douglas T. Summerfield ${ }^{3}$, Amine N. Issa ${ }^{2}$, \& Bruce D. Johnson ${ }^{2}$

\section{Author Affiliations}

${ }^{1}$ Faculty of Biological Sciences, School of Biomedical Sciences, University of Leeds, UK

${ }^{2}$ Division of Cardiovascular Diseases, Department of Internal Medicine, Mayo Clinic and Foundation, USA

${ }^{3}$ Critical Care Medicine, Department of Internal Medicine, Mayo Clinic and Foundation, USA

\section{Contact Information}

Bryan J. Taylor, $\mathrm{PhD}$

University Academic Fellow

School of Biomedical Sciences

Faculty of Biological Sciences

University of Leeds

Garstang 5.68

Leeds, UK

LS2 9JT

Office: $+44(0) 1133430482$

E-mail:b.j.taylor@leeds.ac.uk 


\title{
Highlights (for review)
}

1. We aimed to assess lung fluid balance before and after gradual ascent to 5,150 m;

2. Lung diffusing capacity increased from sea-level to high-altitude;

3. Alveolar-capillary membrane conductance also increased from sea-level to high-altitude;

4. Gradual non-significant reduction in ultrasound lung comets with altitude;

5. Evidence of a decrease in interstitial lung fluid relative to at sea-level with gradual ascent to high-altitude.

\begin{abstract}
We aimed to assess lung fluid balance before and after gradual ascent to 5,150 $\mathrm{m}$. Lung diffusion capacity for carbon monoxide (DLCO), alveolar-capillary membrane conductance (Dmco) and ultrasound lung comets (ULCs) were assessed in 12 healthy lowlanders at sea-level, and on Day 1, Day 5 and Day 9 after arrival at Mount Everest Base Camp (EBC). EBC was reached following an 8-day hike at progressively increasing altitudes starting at 2,860 m. DLCO was unchanged from sea-level to Day 1 at EBC, but increased on Day $5(11 \pm 10 \%)$ and Day $9(10 \pm 9 \%)$ vs. sea-level $(P \leq 0.047)$. Dmco increased from sea-level to Day $1(9 \pm 6 \%)$, Day $5(12 \pm 8 \%)$, and Day $9(17 \pm 11 \%)$ (all $\mathrm{P} \leq 0.001$ ) at EBC. There was no change in ULCs from sea-level to Day 1, Day 5 and Day 9 at EBC. These data provide evidence that interstitial lung fluid remains stable or may even decrease relative to at sea-level following 8 days of gradual exposure to high-altitude in healthy humans.
\end{abstract}

Key words: Hypoxia; high-altitude pulmonary edema; lung diffusing capacity; ultrasound lung comets. 


\section{Introduction}

The volume of extravascular pulmonary fluid is determined by Starling's Law and is a function of pulmonary capillary fluid extrusion relative to the rate of fluid reabsorption from the pulmonary interstitial compartments Bates et al., 2011, Butler et al., 1999. Fluid flux across the pulmonary vasculature is reflected by the balance between the hydrostatic pressure in the pulmonary capillaries and the hydrostatic pressure in the interstitial space, as well as the permeability of the pulmonary capillaries to fluid. Fluid clearance or reabsorption from the pulmonary interstitium is largely dependent on the activity of the thoracic lymph ducts Bates et al., 2011 and $\mathrm{Na}^{+}$transport systems located apically on the alveolar surface that actively reabsorb lung fluid that has permeated the alveolar-capillary membrane Matthay et al., 2002, Mutlu et al., 2004.

Exposure to high-altitude is associated with a substantial increase in pulmonary capillary hydrostatic pressure due to hypoxic pulmonary vasoconstriction Maggiorini et al., 2001, Naeije et al., 2010, increased pulmonary vascular leakage secondary to endothelial dysfunction Richalet, 1995), and inhibition of the epithelial $\mathrm{Na}^{2+}$ transport systems central to lung fluid clearance (Sartori et al., 2010). In combination, these changes in the pulmonary system associated with high-altitude would be expected to disturb lung fluid balance such that a subclinical increase in interstitial lung fluid should occur.

Despite the aforementioned considerations, the evidence for a change in lung fluid balance in healthy lowlanders who sojourn at high-altitude remains equivocal Cogo and Miserocchi, 2011, Swenson, 2011, with some but not all reporting a subclinical increase in interstitial lung fluid \begin{tabular}{|l|l|l|l|}
\hline Agostoni et al., 2013; & Bouzat et al., 2013 & Cremona et al., 2002, de Bisschop et al., 2012, Dehnert \\
\hline
\end{tabular} et al., 2010: Pratali et al., 2010). It has, however, been suggested that very rapid, acute exposure to high-altitude causes a transient, but significant, accumulation of lung fluid Agostoni et al., 2013, 


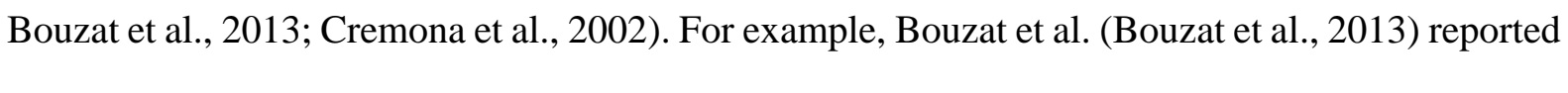
an increase in the number of ultrasound lung comet-tails, a robust index of changes in alveolarinterstitial fluid Agricola et al., 2005, Picano and Pellikka, 2016, in healthy subjects transported by helicopter to $4,250 \mathrm{~m}$ ( 10 $\mathrm{min})$. Interestingly, prolonged exposure and gradual adaptation to high-altitude appears to be associated with a progressive normalisation (after $\sim 2$ weeks) de Bisschop et al., 2012) and subsequent reduction in lung fluid relative to sea-level values (after $\sim 3$ weeks) that may be related to an increase in sympathetic tone Agostoni et al., 2011. Taken together, these previous findings suggest that rapid exposure to high-altitude may facilitate a transient, asymptomatic increase in lung fluid in healthy humans that reverses with a period of acclimatization, possibly due to a sympathetically mediated upregulation of lung fluid clearance mechanisms Agostoni et al., 2011: Sartori et al., 2002 1.

However, whether extravascular lung fluid accumulation occurs in healthy, recreational climbers gradually exposed to high-altitude (i.e. over 6-10 days) remains uncertain and requires further investigation. Accordingly, the aim of the present study was to assess changes in 1) lung diffusing capacity and alveolar-capillary membrane conductance, 2) ultrasound lung comets, and 3) pulmonary function in healthy lowlanders from before to after gradual exposure to $5,150 \mathrm{~m}$. We hypothesised that gradual exposure to high-altitude would not change lung fluid balance relative to at sea-level, as evidenced by no change in lung diffusing capacity, alveolar-capillary membrane conductance, ultrasound lung comets, and pulmonary function. Importantly, it has been suggested that each of these measures provide an accurate index of changes in lung fluid balance Agostoni \begin{tabular}{|l|l|l|l|l|}
\hline et al., 2003: & Agricola et al., 2005: & Cremona et al., 2002, Dehnert et al., 2010; Jambrik et al., 2004, \\
\hline
\end{tabular} Picano and Pellikka, 2016, Snyder et al., 2006). In addition, heart-rate variability was measured as an index of autonomic tone before, during and after the expedition. 


\section{Materials and methods}

\subsection{Subjects}

Twelve healthy non-smoking adult lowlanders ( 2 female) with no history of cardiorespiratory or metabolic disease participated in the study (mean \pm SD; age $=36 \pm 11$ years, stature $=178 \pm 8 \mathrm{~cm}$, body mass $=79.7 \pm 12.7 \mathrm{~kg}$ ). The subjects were physically active ( $\geq 30 \mathrm{~min}$ physical activity/day, $\geq 5$ days/week; self-reported) and had normal forced vital capacity ( $\mathrm{FVC}=109 \pm 12 \%$ of predicted), forced expiratory volume in $1 \mathrm{~s}\left(\mathrm{FEV}_{1}=103 \pm 9 \%\right.$ of predicted $), \mathrm{FEV}_{1} / \mathrm{FVC}$ ratio $(95 \pm 7 \%$ of predicted) and maximal mid-expiratory flow $(\mathrm{MMEF}=106 \pm 14 \%$ of predicted $)$ at sea-level. Each participant gave written informed consent after being provided a detailed description of the study requirements. The experimental procedures were approved by the Mayo Clinic Institutional Review Board and were performed in accordance with the ethical standards of the Declaration of Helsinki. All study participants were prohibited from prophylactic administration of any medication to aid altitude acclimatization (e.g., sildenafil, acetazolamide). Moreover, no subject required emergent pharmaceutical treatment (e.g., dexamethasone) for high altitude illness.

\subsection{Experimental procedures}

Arterial oxygen saturation $\left(\mathrm{SaO}_{2}\right)$ (via transcutaneous pulse oximetry) and heart-rate (HR) (via telemetry) were measured with the participants at rest in the supine position before pulmonary function was assessed using a spirometer according to standard procedures Miller et al., 2005). Next, systolic pulmonary artery pressure (sPAP) and the number of ultrasound lung comets (ULCs) were obtained using transthoracic sonography. Finally, lung diffusing capacity for carbon monoxide and nitric oxide (DLCO and DLNO) were measured. This sequence of measurements was performed in each participant at sea-level (Rochester, MN, USA; elevation $401 \mathrm{~m}$ ), on Day 1 (within 24 hours), Day 5 and Day 9 after arrival at Mount Everest Base Camp (elevation 5,150 m), and within 2 weeks of returning to sea-level after the expedition. To reach Everest Base Camp, 
each participant travelled to Kathmandu, Nepal (elevation 1,400 m) before being transported by airplane to Lukla, Nepal (elevation 2,860 m). From Lukla, the participants completed an 8-day hike at progressively increasing altitudes to reach Mount Everest Base Camp. Once at Everest Base Camp, the participants were free to move about the camp but were instructed to avoid strenuous exercise activities. All meals were served by local support staff and the intake of water was allowed ad libitum.

\subsection{Pulmonary artery pressure}

SPAP was estimated from the peak velocity of tricuspid regurgitation (TR) using a modified Bernoulli equation as described previously Taylor et al., 2011, Yock and Popp, 1984. With the participants in the left lateral supine position, the TR jet was located using 2D-color Doppler echocardiography (SonoSite Edge, FUJIFILM SonoSite Inc., Bothell, WA, USA). To determine the maximal velocity of the TR jet, the continuous wave sampler was positioned within and parallel to the regurgitation jet and sPAP was computed as $4 \mathrm{TR}^{2}$ added to an assumed right atrial pressure of $5 \mathrm{mmHg}$.

\subsection{Lung diffusing capacity}

DLCO, DLNO, alveolar-capillary membrane conductance (Dmco) and pulmonary capillary blood volume (Vc) were assessed as we have described previously Coffman et al., 2016b; Taylor et al., 2016. With subjects in the sitting position, DLCO and DLNO were assessed by simultaneously measuring the disappearance of $\mathrm{CO}$ and NO via a rapid single breath technique using an automated device for performing gas calibrations, extemporaneous mixing of gases and calculations (Hyp'air Compact, Medisoft, Dinant, Belgium) de Bisschop et al., 2012, Pavelescu et al., 2013. For each single breath maneuver, the participants were instructed to breathe normally on environmental air for 4-5 breaths before exhaling slowly and completely down to residual volume (RV). Once at RV, the participants were switched to an inspiratory reservoir filled with $2600 \mathrm{ppm} \mathrm{CO}, 40 \mathrm{ppm} \mathrm{NO}$, 
$8 \% \mathrm{He}, 21 \% \mathrm{O}_{2}$ and $\mathrm{N}_{2}$ balance, and told to inspire rapidly and fully to total lung capacity before holding their breath for $4 \mathrm{~s}$. After the breath hold, the participants then exhaled steadily and swiftly back to RV. The first $0.9 \mathrm{~L}$ of the expired gas was discarded to ensure dead-space wash out with the next $0.9 \mathrm{~L}$ of the expirate collected for subsequent analysis. The single breath maneuver was performed in triplicate at sea-level (pre-expedition), on Day 1, Day 5 and Day 9 after arrival at Mount Everest Base Camp (elevation 5,150 m), and within 2 weeks of returning to sea-level after the expedition. Each measure of DLCO and DLNO was separated by four minutes later, according to current guidelines Macintyre et al., 2005.

Following the assessment of lung diffusing capacity, Dmco and Vc were computed as described previously de Bisschop et al., 2012, Glenet et al., 2007, Pavelescu et al., 2013. Based on the molecular weight and solubility of CO and NO, the coefficient relating DLNO to Dmco was set at 1.97 Aguilaniu et al., 2008 such that Dmco was calculated as the measured DLNO/1.97. Then, to solve the Roughton and Forster equation Roughton and Forster, 1957, 1/Ө co was calculated using an equation proposed by Forster expressing the blood conductance of $\mathrm{CO}$ (i.e. $\Theta_{\mathrm{co}}$ ) as a function of capillary $\mathrm{PO}_{2}$ Forster, 1987:

$$
1 / \Theta_{\mathrm{CO}}=1.3+0.0041 \times \mathrm{PcapO}_{2}
$$

where $\mathrm{PcapO}_{2}$ is the capillary pressure of $\mathrm{O}_{2}$, estimated as alveolar $\mathrm{PO}_{2}-\dot{\mathrm{VO}}_{2} /(\mathrm{DLCO} \times 1.23)$ with partial pressures in $\mathrm{mmHg}, \dot{\mathrm{V}} \mathrm{O}_{2}$ in $\mathrm{ml} / \mathrm{min}$, and DLCO in $\mathrm{ml} / \mathrm{min} / \mathrm{mmHg}$. Based on the measured barometric pressure $(\sim 400 \mathrm{mmHg})$ and the expired fraction of $\mathrm{O}_{2}$, the calculated alveolar $\mathrm{PO}_{2}$ at Everest Base Camp ranged from 52-60 mmHg. $\dot{\mathrm{VO}}_{2}$ was calculated using the mass balance of $\mathrm{O}_{2}$ between inspiration and expiration during the single breath maneuver and DLCO $\times 1.23$ was used as a surrogate for $\mathrm{DLO}_{2}$ Forster, 1987. Using this equation, $\mathrm{PcapO}_{2}$ was calculated at $\sim 116 \mathrm{mmHg}$ and $\sim 50 \mathrm{mmHg}$ at sea-level and Everest Base Camp, respectively; these values are similar to those 
recently reported under similar conditions de Bisschop et al., 2012. Venous blood was sampled for hemoglobin $(\mathrm{Hb})$ concentration and $\mathrm{Vc}$ was corrected accordingly for standard concentrations of $\mathrm{Hb}$ in men (14.6 g/dl) and women (13.4 g/dl) Macintyre et al., 2005) as measured Vc $\times($ standard $\mathrm{Hb}$ concentration/measured $\mathrm{Hb}$ concentration). To allow comparison between DLCO measured at sea-level and high-altitude, DLCO at Everest Base Camp was recalculated using the Dmco and Vc values computed at high-altitude and the sea-level (i.e. normoxic) Өco as follows Pavelescu et al., 2013 :

\section{$1 / \mathrm{DLCO}_{\mathrm{ALT}}=1 / \mathrm{Dm}_{\mathrm{COALT}}+1 / \Theta_{\mathrm{CCO}} \cdot \mathrm{Vc}_{\mathrm{ALT}}$}

where, Dmcoalt and Vcalt are the alveolar-capillary membrane conductance and pulmonary capillary blood volume, respectively, calculated at Everest Base Camp using the hypoxic Өco and $\Theta_{\mathrm{CO} s \mathrm{~s}}$ is the $\Theta_{\mathrm{co}}$ at sea-level (i.e. the normoxic $\Theta_{\mathrm{co}}$ ).

\subsection{Ultrasound lung comets}

The number of ULCs was determined via transthoracic sonography, as described previously \begin{tabular}{|l|l|}
\hline Bouzat et al., 2013 Picano and Pellikka, 2016. With participants in the supine position, sequential & \\
\hline
\end{tabular} examination of 28 intercostal lung fields located at the parasternal, midclavicular, anterior axillary and mid-axillary lines from the second to the fourth intercostal space on the left side and from the second to the fifth intercostal space on the right side was completed using a portable ultrasound (SonoSite Edge, FUJIFILM SonoSite Inc., Bothell, WA, USA) integrated with a cardiac probe. An ULC was defined as an echogenic, coherent, wedge-shaped signal that originated from the hyperechoic pleural line and extended to the edge of the screen. The presence of an ULC was simultaneously verified by two trained operators throughout the study (BT and DS) and the total number of ULCs identified was recorded for each participant. 


\subsection{Heart-rate variability}

With subjects at rest and in the supine position, cardiac rhythm was recorded using a custom built 3-lead ECG during: 1) 5-min of spontaneous breathing, and 2) 5-min of paced breathing (6 breaths/min). For the paced breathing trial, subjects maintained the respiratory frequency of 6 breaths/min by following a metronome with distinct inspiratory and expiratory tones. Lead II electrocardiograph signals were extracted and recorded at $1000 \mathrm{~Hz}$ using a data acquisition system (Cardiocap/5, Datex-Ohmeda Inc., Louisville, CO, USA), and beat-by-beat cardiac intervals (RR interval) were extracted from the raw electrocardiograph traces during the spontaneous breathing and paced breathing trials. Time-domain parameters, namely standard deviation of normal-tonormal beats (SDNN) and root mean square of successive differences in intervals (RMSSD), were derived using custom designed Matlab software (version 7.7.0, The Mathworks Inc., Natick, MA, USA) and used to estimate cardiac autonomic activity as previously described Stewart et al., 2016. These measures were made in a subset of 8 subjects at sea-level (pre-expedition), on Day 1, Day 5 and Day 9 after arrival at Everest Base Camp, and at sea-level within 2 weeks postexpedition.

\subsection{Statistical analyses}

One-way repeated measures ANOVA was used to compare absolute measures of systolic pulmonary artery pressure, lung diffusing capacity and related variables (DLCO, Dmco, Dmco/Vc), the number of ultrasound lung comets, pulmonary function, and heart rate variability across time (sea-level pre-expedition vs. Everest Base Camp Day 1 vs. Everest Base Camp Day 5 vs. Everest Base Camp Day 9 vs. sea-level post-expedition). Following significant main effects, planned pairwise comparisons were made using the Bonferroni method. The acceptable type I error was set at $\mathrm{P}<0.05$. Data are expressed as group means \pm SD. Statistical analyses were performed using SPSS version 22.0 for Windows (SPSS, Chicago, IL). 


\section{Results}

\subsection{General effects of high altitude}

Overall, exposure to high-altitude was associated with only mild, transient headache and fatigue/weakness in our participants. On the morning of Day 1, Day 5, and Day 9 at Everest Base Camp, group mean Lake Louise score was not positive for the presence of acute mountain sickness (Table 1). From sea-level to high-altitude, there was significant and sustained decrease in resting $\mathrm{SaO}_{2}$, and an increase in resting $\mathrm{HR}$ and haemoglobin concentration (Table 1).

\subsection{Systolic pulmonary artery pressure}

Relative to pre-expedition sea-level values, there was an increase in group mean sPAP on Day 1 $(62 \pm 40 \%, \mathrm{P}=0.001)$, Day $5(78 \pm 51 \%, \mathrm{P}=0.001)$, and Day $9(64 \pm 47 \%, \mathrm{P}=0.005)$ at Everest Base Camp (Figure 1). Group mean sPAP decreased back to pre-expedition baseline values within 2 weeks of return to sea-level (Figure 1).

\subsection{Lung diffusing capacity}

Group mean and individual subject resting measures of DLCO, Dmco, and Dmco/Vc at sea-level (pre- and post-expedition) and at high-altitude are shown in Figure 2. Group mean DLCO was unchanged from sea-level pre-expedition to Day 1 at Everest Base Camp (38.3 \pm 5.0 vs. $40.5 \pm 6.8$ $\mathrm{ml} / \mathrm{min} / \mathrm{mmHg}, \mathrm{P}=0.157$ ), but was significantly elevated on Day 5 and Day 9 at Everest Base Camp relative to pre-expedition sea-level values $(11 \pm 10 \%, \mathrm{P}=0.045$ and $10 \pm 9 \%, \mathrm{P}=0.047$, respectively) (Figure 2). Similarly, group mean Dmco increased from sea-level pre-expedition to Day $1(9 \pm 6 \%, \mathrm{P}=0.003)$, Day $5(12 \pm 8 \%, \mathrm{P}=0.003)$, and Day $9(17 \pm 11 \%, \mathrm{P}=0.001)$ at Everest Base Camp. In addition, Dmco was greater on Day 9 compared to Day 1 at Everest Base Camp (102 \pm 12 vs. $96 \pm 11 \mathrm{ml} / \mathrm{min} / \mathrm{mmHg}, \mathrm{P}=0.034)$ (Figure 2). There was no change in group mean Vc from sea-level pre-expedition $(124 \pm 30 \mathrm{ml})$ to Day $1(134 \pm 34 \mathrm{ml})$, Day $5(130 \pm 29 \mathrm{ml})$ and 
Day $9(129 \pm 29 \mathrm{ml})$ at Everest Base Camp (all $\mathrm{P} \geq 0.268)$. Accordingly, there was an increase in group mean Dmco/Vc from sea-level pre-expedition to Day $1(3 \pm 4 \%)$, Day 5 (8 $\pm 12 \%)$, and Day $9(14 \pm 15 \%)$ at Everest Base Camp; however, only the change from sea-level to Day 9 was statistically significant $(\mathrm{P}=0.036)$ (Figure 2). DLCO, Dmco, and Dmco/Vc returned to preexpedition baseline values within 2 weeks of the end of the expedition (Figure 2).

\subsection{Ultrasound lung comets}

The total number of ULCs in the right and left lung was normal in each participant at sea-level prior to the expedition (mean $=1.9 \pm 2.0$, range $=0-6$ ) (Figure 3). Although not statistically significant, there was a trend towards a gradual reduction in the number of ULCs from preexpedition sea-level values to Day 1, Day 5 and Day 9 at Everest Base Camp (Figure 3). The total number of ULCs within 2 weeks after the end of the expedition (1.6 \pm 1.5 , range $0-5)$ were very similar to pre-expedition baseline values (Figure 3).

\subsection{Pulmonary function}

Group mean $\mathrm{FVC}, \mathrm{FEV}_{1}, \mathrm{FEV}_{1} / \mathrm{FVC}$ ratio and $\mathrm{MEF}_{25-75 \%}$ at sea-level (pre- and post-expedition) and at high-altitude are shown in Table 2. There was no change in group mean FVC, FEV $\mathrm{FEV}_{1} / \mathrm{FVC}$ ratio from sea-level (pre-expedition) to Day 1, Day 5, and Day 9 at Everest Base Camp. By contrast, $\mathrm{MEF}_{25-75 \%}$ was greater on Day 5 and Day 9 at Everest Base Camp compared to preexpedition sea-level values $(10 \pm 8 \%, \mathrm{P}=0.045$ and $13 \pm 10 \%, \mathrm{P}=0.026)$. Additionally, $\mathrm{MEF}_{25}$ 75\% was greater on Day 5 compared to Day 1 at Everest Base Camp $(\mathrm{P}<0.001)$ (Table 2). Group mean $\mathrm{MEF}_{25-75 \%}$ decreased back to pre-expedition baseline values within 2 weeks of return to sealevel (Table 2).

\subsection{Heart-rate variability}


Group mean SDNN and RMSSD during spontaneous and paced breathing (6 breaths/min) are shown in Table 3. There was a substantial but non-statistically significant reduction in SDNN during both spontaneous and paced breathing from pre-expedition sea-level values to Day 1, Day 5 and Day 9 at Everest Base Camp (Table 3). Similarly, there was a non-significant reduction in group mean RMSSD during paced breathing at Day 1, Day 5 and Day 9 at Everest Base Camp relative to at sea-level (pre-expedition); no such trend was observed in RMSSD during spontaneous breathing (Table 3). Both group mean SDNN and RMSSD during paced breathing were, however, significantly lower at sea-level post-expedition compared to at sea-level pre-expedition $(\mathrm{P}=0.018$ and $\mathrm{P}=0.003$, respectively) (Table 3).

\section{Discussion}

\subsection{Main findings}

In the present study, 12 healthy lowlanders completed an 8-day hike (starting at 2,860 m) at progressively increasing altitudes to reach Mount Everest Base Camp (5,150 m), and then stayed at this altitude for 10 days before returning to sea-level. The changes in systolic pulmonary artery pressure (sPAP), lung diffusing capacity, ultrasound lung comets (ULCs), and pulmonary function from sea-level to high-altitude were assessed. In addition, heart-rate variability was measured in 8 subjects as index of cardiac autonomic activity before, during and after the expedition. The major findings were: 1) there was a substantial and sustained increase in SPAP from sea-level to highaltitude, indicating the presence of hypoxic pulmonary vasoconstriction, 2) lung diffusing capacity for carbon monoxide was unchanged from sea-level to Day 1 at Everest Base Camp, but was significantly increased on Day 5 and Day 9 relative to pre-expedition sea-level values, 3) alveolarcapillary membrane conductance (Dmco) increased progressively from sea-level to Day 1, Day 5, and Day 9 at Everest Base Camp, with a concomitant increase in the Dmco to pulmonary capillary blood volume ratio $(\mathrm{Dmco} / \mathrm{Vc}), 4)$ there was no change in the number of ULCs from pre-expedition sea-level values to Day 1, Day 5 and Day 9 at Everest Base Camp, 5) mid-expiratory flow rate 
$\left(\mathrm{MMEF}_{25-75 \%)}\right.$ was greater on Day 5 and Day 9 at Everest Base Camp compared to pre-expedition sea-level values; there was no sea-level to high-altitude change in any other measure of pulmonary function, and 6) there was a substantial but non-statistically significant reduction in SDNN (spontaneous and paced breathing) and RMSSD (paced breathing only) from pre-expedition sealevel values to Day 1, Day 5 and Day 9 at Everest Base Camp. In combination, these data provide evidence that interstitial lung fluid remains stable, and may even decrease slightly, relative to sealevel values following just 8 days of gradual exposure to high-altitude in healthy humans. Although somewhat speculative, it is possible that a hypoxia-mediated increase in sympathetic tone is the primary cause of this reduction in lung fluid at high-altitude.

\subsection{Technical considerations}

\subsubsection{The use of indirect measures of interstitial lung fluid}

One concern is that measures of lung diffusing capacity and ULCs provide only an indirect measure of lung fluid balance. However, it has been shown that a short term decrease in DLCO is consistent with an increase in extravascular lung water, particularly if the reduction in DLCO is primarily mediated by a decrease in gas conductance across the alveolar-capillary membrane (i.e. Dmco) Agostoni et al., 2003. Indeed, previous data from our laboratory demonstrated a significant increase in CT derived measures of lung fluid with a concomitant decrease in Dmco following experimentally-induced pulmonary oedema in healthy humans Snyder et al., 2006.

'B-lines' or ULCs are thought to originate from reflections of discrete air/fluid interfaces between collapsed, fluid-filled, and well aerated alveoli. It is suggested that the appearance of ULCs likely corresponds to a progressive loss of air per volume of lung tissue with a concomitant increase in relative and absolute content of extravascular lung water Picano and Pellikka, 2016. However, it is also possible that an increase in the number of ULCs in response to alveolar hypoxia or highaltitude may simply represent an increase in thoracic lymph flow that is required to prevent 
interstitial fluid accumulation Levine et al., 1988. Additionally, the lack of a strong correlation between ULCs and pulmonary vascular pressures and other indirect indices of a shift in lung fluid balance, including clinical congestion score and lung volumes, may question the utility of this measure. Despite these concerns, it has been reported previously that the number of ULCs correlates well with lung wet/dry ratio in animals and radiologic lung water score in humans, suggesting that the presence of ULCs is indeed a robust measure of changes in interstitial lung fluid \begin{tabular}{|l|l|l|}
\hline Agricola et al., 2005, Jambrik et al., 2010, Jambrik et al., 2004, & Picano and Pellikka, 2016. \\
\hline
\end{tabular}

Based on the aforementioned considerations, it appears that the measures of lung diffusing capacity, especially Dmco, and ULCs used in the present study provide an accurate index of changes in lung fluid balance. Accordingly, we are confident in our conclusion that lung fluid volume remains stable, and may even decrease slightly, relative to sea-level values in healthy humans gradually acclimatised to high-altitude.

\subsubsection{Assumption that $\theta_{\text {No }}$ is infinite}

We have addressed the considerations regarding the use of a defined $\Theta_{\mathrm{NO}}$ value (i.e. 4.5 $\mathrm{ml} / \mathrm{min} / \mathrm{mmHg}$ ) in previous publications \begin{tabular}{l|l|l|}
\hline Coffman et al., 2016a & Coffman et al., 2016b & Taylor et \\
\hline
\end{tabular} al., 2016. While the use of this specific finite $\Theta_{\mathrm{NO}}$ in the calculation of Dmco and Vc has recently been recommended Zavorsky et al., 2017), we believe this remains a matter of debate for several reasons. Although it has been estimated that $37 \%$ of the resistance to NO uptake lies in the

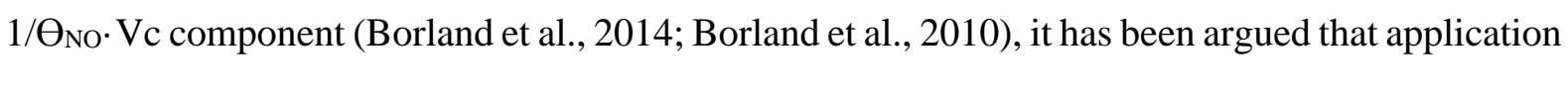
of this figure in the whole body human must be treated with caution as its calculation involved exchange transfusion in dogs, substituting bovine Hb-glutamer 200 for whole blood Hughes and van der Lee, 2013. Additionally, it has also been estimated that DLNO would not need to be adjusted unless the hemoglobin concentration is $<8 \mathrm{~g} / \mathrm{dl}$ Borland et al., 2010. Thus, it can be postulated that if the overall binding or mass transfer of NO to hemoglobin is not affected by a 
substantial lowering of $\mathrm{Hb}$ concentration (until lower than $8 \mathrm{~g} / \mathrm{dL}$ ), then the resistance proposed to be provided by the red blood cell to NO (i.e. $\Theta_{\mathrm{NO}}$ ) would not have any major physiological effect on the measurement of alveolar-capillary membrane conductance. Accordingly, there is currently no consensus on the application of the assumption of a finite value for $\Theta_{\mathrm{NO}}$ in the calculation of Dmco and Vc in humans. Furthermore, in our experience, application of a finite $\Theta_{\mathrm{NO}}$ of 4.5 $\mathrm{ml} / \mathrm{min} / \mathrm{mmHg}$ typically results in Dmco values that are excessively large and do not compare favorably to values previously reported in whole body humans de Bisschop et al., 2012. As such, in the present manuscript we calculate Dmco and $V_{c}$ based on the assumption that $\Theta_{\mathrm{NO}}$ is infinite.

\subsection{Changes in lung fluid balance with hypoxia and at high-altitude: comparison to previous}

\section{studies}

Exposure to high-altitude is associated with a hypoxia-mediated increase in pulmonary capillary hydrostatic pressure Maggiorini et al., 2001, Naeije et al., 2010 as well as an increase in pulmonary vascular leakage (Richalet, 1995) and an inhibition of the epithelial $\mathrm{Na}^{2+}$ transport systems central to lung fluid clearance (Sartori et al., 2010). Theoretically, these changes may conspire to disturb lung fluid balance such that an increase in interstitial lung fluid would occur at high-altitude. However, despite the aforementioned considerations, the evidence for a change in lung fluid balance in healthy lowlanders who sojourn at high-altitude remains equivocal Cogo and Miserocchi, 2011, Swenson, 2011.

While cases of overt high-altitude pulmonary oedema (HAPE) are somewhat rare Hackett et al., 1976, Maggiorini et al., 1990, it has been suggested by some that subclinical interstitial pulmonary oedema is far more prevalent in lowlanders rapidly exposed to high-altitude Agostoni et al., 2013,

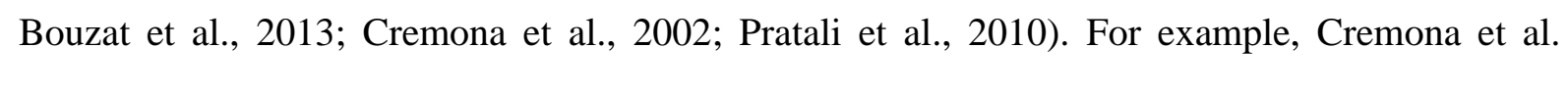
Cremona et al., 2002) reported a $25 \%$ increase in closing volume, thought to be indicative of airway compression secondary to peribronchial cuffs of fluid, in $\sim 75 \%$ of climbers who ascended 
from 1,200 m to 4,559 m in 24 hours. Similarly, Agostoni et al. Agostoni et al., 2013 found a significant reduction in alveolar-capillary membrane conductance (Dmco) $(\sim 5.4-7.4$ $\mathrm{ml} / \mathrm{min} / \mathrm{mmHg}$ ), which is thought to consistent with an increase in extravascular lung water, in healthy lowlanders who climbed to 4,559 $\mathrm{m}$ in $<36$ hours. Conversely, Dehnert et al. Dehnert et al., 2010 reported no change in total lung capacity, forced vital capacity, closing volume and lung compliance from low- to high-altitude in healthy humans who climbed to $4,559 \mathrm{~m}$ in $<24$ hours. It must be stressed, however, that subjects with evidence of mild alveolar edema on chest radiographs did experience minor decreases in forced vital capacity, diffusing capacity and lung compliance and minor increases in closing volume Dehnert et al., 2010, perhaps questioning the sensitivity of lung function tests for the detection of very mild interstitial pulmonary fluid accumulation. Taken together, the aforementioned findings suggest that rapid, acute exposure to high-altitude causes a small, asymptomatic accumulation of interstitial lung fluid in otherwise healthy humans, although does remain a matter of debate Cogo and Miserocchi, 2011, Swenson, 2011.

By contrast, it has been shown that short-term exposure to normobaric hypoxia has no effect on lung wet weight or may even decrease lung fluid in healthy animals and humans Aarseth et al.,

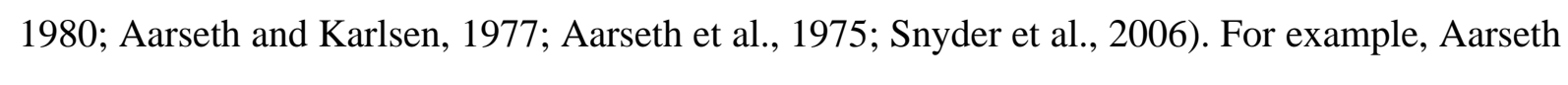
and Karlsen reported a rapid and marked reduction in both pulmonary blood volume and extravascular water content in rats exposed to $10 \% \mathrm{O}_{2}$ Aarseth and Karlsen, 1977. Similarly, a 17-hour exposure to $\sim 12.5 \% \mathrm{O}_{2}$ decreased lung tissue volume (approximately $-150 \mathrm{ml}$ ) and extravascular lung water (approximately $-75 \mathrm{ml}$ ) in healthy adult humans Snyder et al., 2006. While we and others have previously suggested that lung fluid regulation may be different in response to normobaric vs. hypobaric hypoxia Girard et al., 2012, it does appear that prolonged exposure and subsequent gradual adaptation to high-altitude is accompanied by normalisation and perhaps even a reduction in lung fluid relative to sea-level values in humans Agostoni et al., 2011, de Bisschop et al., 2012. For example, Agostoni et al. Agostoni et al., 2011 assessed DLCO, 
Dmco and Vc in 33 healthy lowlanders at sea-level and again after a 9 day trek to followed by a 2 week residence at $5,400 \mathrm{~m}$. The authors reported that, relative to sea-level, there was a $\sim 1.5$ $\mathrm{ml} / \mathrm{min} / \mathrm{mmHg}$ and a $\sim 39.0 \mathrm{ml} / \mathrm{min} / \mathrm{mmHg}$ increase in DLCO and Dmco, respectively, following 3 weeks at high-altitude despite a $\sim 60 \%$ increase in pulmonary artery systolic pressure. These increases were paralleled with a significant rise in plasma epinephrine concentration, which is suggestive of an increase in sympathetic tone Agostoni et al., 2011. These data suggest that gradual, prolonged exposure to high-altitude ( $\sim$ weeks) results in a decrease in interstitial lung fluid that may, at least in part, be mediated by an upregulation of fluid clearance mechanisms secondary to an increase in sympathetic drive. Presently, we found that a slow ascent and gradual adaptation to high-altitude caused a significant increase in DLCO ( 10-11\%) and Dmco ( 9-17\%) along with no change in the number of ultrasound lung comets relative to sea-level in 12 healthy lowlanders. In the present study, however, the aforementioned changes, which are indicative of a reduction in interstitial lung fluid, were apparent on Day 1 at Everest Base Camp; that is, after only 8 days at high-altitude. These changes occurred despite a substantial and sustained increase in sPAP from sea-level to high-altitude $(\sim 68 \%)$ and were coincident with a substantial, but non-significant, decrease in SDNN and RMSSD, which is suggestive of a decrease in cardiac parasympathetic tone. Based on the current findings, we postulate that a sympathetically mediated stimulation of the beta2 adrenergic system facilitates clearance or reabsorption of interstitial lung fluid at a rate greater than fluid extrusion of the pulmonary capillaries secondary to significant hypoxic pulmonary vasoconstriction, even after only 8 days of gradual adaptation to high-altitude.

\subsection{Potential mechanisms by which lung fluid is cleared at high-altitude}

A reduction in interstitial lung fluid, and the associated increase in DLCO and gas conductance across the alveolar-capillary membrane (i.e. increased Dmco), in healthy lowlanders gradually acclimatised to high-altitude likely serves to improve alveolar-capillary $\mathrm{PO}_{2}$ equilibration and thus minimise the reduction $\mathrm{SaO}_{2}$ that accompanies exposure to high-altitude. In addition, the potential 
importance of an increase in DLCO and Dmco in better maintaining $\dot{\mathrm{V}}{ }_{2 m a x}$ at high-altitude was demonstrated by Wagner Wagner, 1996. Using a theoretical numerical analysis of the influence of the lungs, circulation and muscles on $\mathrm{V}_{2 \max }$, the author reported that neither the fall in maximal cardiac output nor the increase in haemoglobin concentration associated with chronic hypoxia affected $\dot{\mathrm{V}} \mathrm{O}_{2 \max }$. By contrast, with increasing altitude there was a progressive increase in the influence of lung diffusion capacity on $\dot{\mathrm{V}} \mathrm{O}_{2 \max }$, with high values of lung diffusing capacity appearing to be advantageous for exercise at high-altitude Wagner, 1996.

There are several mechanisms by which gradual acclimatization to high-altitude may have resulted in a decrease in interstitial lung fluid volume in our subjects in the present study. Based on the following evidence, we suggest that the reduction in extravascular lung water associated with gradual adaptation to high-altitude in the present study was due to activation of the $\beta_{2}$-ARs secondary to a large hypoxia-mediated increase in sympathetic drive. It is likely that stimulation of beta-2 adrenergic receptors ( $\beta_{2}$-ARs) secondary to sympathetic activation at high-altitude improved fluid clearance from the pulmonary interstitium. The $\beta_{2}$-ARs are expressed throughout the pulmonary system, including in the airways, the alveolar spaces, the pulmonary vasculature and the pulmonary lymphatic tissue, and stimulation of these receptors activates $\mathrm{Na}^{2+}$ transport systems located apically on the alveolar surface that act to reabsorb lung fluid that has permeated the alveolar-capillary barrier Matthay et al., 2002, Mutlu et al., 2004. In addition, it has been shown that stimulation of the $\beta_{2}$-ARs on lymphatic tissue causes dilation as well as active phasic contraction of the thoracic lymphatic ducts, which acts to clear lung fluid from the perivascular spaces to the hilar lymph nodes Ikomi et al., 1991, Mahe et al., 1991. Moreover, $\beta_{2}$-AR stimulation appears to tighten the cell-to-cell contacts within the vascular endothelium, which in turn would be expected to decrease pulmonary capillary permeability and reduce fluid flux into the lung interstitial space Allen and Coleman, 1995. Finally, administration of the long acting $\beta_{2}-\mathrm{AR}$ agonist salmeterol resulted in a $\sim 50 \%$ decrease in the incidence of high-altitude pulmonary oedema 
(HAPE) in HAPE susceptible but otherwise healthy humans Sartori et al., 2002. It must be stressed, however, that owing to the multiple actions of $\beta_{2}$-AR agonists, including inhibition of hypoxic pulmonary vasoconstriction and upregulation of NO production, whether the prevention of HAPE was as a direct result of enhanced lung fluid clearance remains uncertain Bartsch and Mairbaurl, 2002).

\subsection{Conclusions}

In conclusion, gradual adaptation to high-altitude may cause a decrease in interstitial lung fluid volume in healthy lowlanders, as evidenced by an increase in lung diffusing capacity for carbon monoxide and alveolar-capillary membrane conductance, and a trend towards a reduction in the number of ultrasound lung comets. This decrease in extravascular lung water was observed as early as after $\sim 8$ days of high-altitude exposure. Although somewhat speculative, we propose that a hypoxia-mediated activation of the $\beta_{2}$-AR system, which is critical in the regulation of lung fluid, is the likely cause of this reduction in lung fluid in healthy lowlanders at high-altitude.

\section{Funding}

The National Geographic Society, and a grant from the Leslie and Lou Gonda families to Mayo Clinic. Bryan Joseph Taylor was supported by an American Heart Association Postdoctoral Fellowship (AHA grant 12POST12070084).

\section{Conflicts of interest}

No conflicts of interest are declared by the authors

\section{Conflicts of Interest}

None declared 


\section{Acknowledgements}

This study was part of a larger Everest Expedition with funding for Dr. Johnson's laboratory by The North Face Company. The authors appreciate the technical help from Mr. Alex Kasak and all the accompanying members of our Human Integrative and Environmental Physiology laboratory who worked hard to help prepare for the project. This expedition was the 2012 Legacy Climb led by climber Conrad Anchor to celebrate the 50th anniversary of the 1963 American Mt. Everest Expedition.

\section{REFERENCES}

Aarseth, P., Bjertnaes, L., Karlsen, J., 1980. Changes in blood volume and extravascular water content in isolated perfused rat lungs during ventilation hypoxia. Acta Physiol Scand 109, 61-67.

Aarseth, P., Karlsen, J., 1977. Blood volume and extravascular water content in the rat lung during acute alveolar hypoxia. Acta Physiol Scand 100, 236-245.

Aarseth, P., Karlsen, J., Bo, G., 1975. Effects of catecholamine-infusions and hypoxia on pulmonary blood volume and extravascular lung water content in cats. Acta Physiol Scand 95, 3440.

Agostoni, P., Cattadori, G., Bianchi, M., Wasserman, K., 2003. Exercise-induced pulmonary edema in heart failure. Circulation 108, 2666-2671.

Agostoni, P., Swenson, E.R., Bussotti, M., Revera, M., Meriggi, P., Faini, A., Lombardi, C., Bilo, G., Giuliano, A., Bonacina, D., Modesti, P.A., Mancia, G., Parati, G., Investigators, H., 2011. Highaltitude exposure of three weeks duration increases lung diffusing capacity in humans. J Appl Physiol (1985) 110, 1564-1571.

Agostoni, P., Swenson, E.R., Fumagalli, R., Salvioni, E., Cattadori, G., Farina, S., Bussotti, M., Tamplenizza, M., Lombardi, C., Bonacina, D., Brioschi, M., Caravita, S., Modesti, P., Revera, M., Giuliano, A., Meriggi, P., Faini, A., Bilo, G., Banfi, C., Parati, G., 2013. Acute high-altitude exposure reduces lung diffusion: data from the HIGHCARE Alps project. Respir Physiol Neurobiol $188,223-228$.

Agricola, E., Bove, T., Oppizzi, M., Marino, G., Zangrillo, A., Margonato, A., Picano, E., 2005. "Ultrasound comet-tail images": a marker of pulmonary edema: a comparative study with wedge pressure and extravascular lung water. Chest 127, 1690-1695.

Aguilaniu, B., Maitre, J., Glenet, S., Gegout-Petit, A., Guenard, H., 2008. European reference equations for CO and NO lung transfer. Eur Respir J 31, 1091-1097.

Allen, M.J., Coleman, R.A., 1995. Beta 2-adrenoceptors mediate a reduction in endothelial permeability in vitro. Eur J Pharmacol 274, 7-15. 
Bartsch, P., Mairbaurl, H., 2002. Salmeterol for the prevention of high-altitude pulmonary edema. N Engl J Med 347, 1282-1285; author reply 1282-1285.

Bates, M.L., Farrell, E.T., Eldridge, M.W., 2011. The curious question of exercise-induced pulmonary edema. Pulm Med 2011, 361931.

Borland, C., Bottrill, F., Jones, A., Sparkes, C., Vuylsteke, A., 2014. The significant blood resistance to lung nitric oxide transfer lies within the red cell. J Appl Physiol (1985) 116, 32-41.

Borland, C.D., Dunningham, H., Bottrill, F., Vuylsteke, A., Yilmaz, C., Dane, D.M., Hsia, C.C., 2010. Significant blood resistance to nitric oxide transfer in the lung. J Appl Physiol (1985) 108, 1052-1060.

Bouzat, P., Walther, G., Rupp, T., Doucende, G., Payen, J.F., Levy, P., Verges, S., 2013. Time course of asymptomatic interstitial pulmonary oedema at high altitude. Respir Physiol Neurobiol $186,16-21$.

Butler, J., Chomsky, D.B., Wilson, J.R., 1999. Pulmonary hypertension and exercise intolerance in patients with heart failure. J Am Coll Cardiol 34, 1802-1806.

Coffman, K.E., Chase, S.C., Taylor, B.J., Johnson, B.D., 2016a. The blood transfer conductance for nitric oxide: Infinite vs. finite thetaNO. Respir Physiol Neurobiol.

Coffman, K.E., Taylor, B.J., Carlson, A.R., Wentz, R.J., Johnson, B.D., 2016b. Optimizing the calculation of DM,CO and VC via the single breath single oxygen tension DLCO/NO method. Respir Physiol Neurobiol 221, 19-29.

Cogo, A., Miserocchi, G., 2011. Pro: most climbers develop subclinical pulmonary interstitial edema. High Alt Med Biol 12, 121-124; discussion 131-122.

Cremona, G., Asnaghi, R., Baderna, P., Brunetto, A., Brutsaert, T., Cavallaro, C., Clark, T.M., Cogo, A., Donis, R., Lanfranchi, P., Luks, A., Novello, N., Panzetta, S., Perini, L., Putnam, M., Spagnolatti, L., Wagner, H., Wagner, P.D., 2002. Pulmonary extravascular fluid accumulation in recreational climbers: a prospective study. Lancet 359, 303-309.

de Bisschop, C., Martinot, J.B., Leurquin-Sterk, G., Faoro, V., Guenard, H., Naeije, R., 2012. Improvement in lung diffusion by endothelin A receptor blockade at high altitude. J Appl Physiol (1985) 112, 20-25.

Dehnert, C., Luks, A.M., Schendler, G., Menold, E., Berger, M.M., Mairbaurl, H., Faoro, V., Bailey, D.M., Castell, C., Hahn, G., Vock, P., Swenson, E.R., Bartsch, P., 2010. No evidence for interstitial lung oedema by extensive pulmonary function testing at 4,559 m. Eur Respir J 35, 812820.

Forster, R.E., (1987). Diffusion of gases across the alveolar membrane, Handbook of Physiology. The Respiratory System. Gas Exchange. Am Physiol Soc, Bethesda, MD, pp. 71-88.

Girard, O., Koehle, M.S., MacInnis, M.J., Guenette, J.A., Koehle, M.S., Verges, S., Rupp, T., Jubeau, M., Perrey, S., Millet, G.Y., Chapman, R.F., Levine, B.D., Conkin, J., Wessel, J.H., 3rd, Nespoulet, H., Wuyam, B., Tamisier, R., Verges, S., Levy, P., Casey, D.P., Taylor, B.J., Snyder, E.M., Johnson, B.D., Laymon, A.S., Stickford, J.L., Weavil, J.C., Loeppky, J.A., Pun, M., Schommer, K., Bartsch, P., Vagula, M.C., Nelatury, C.F., 2012. Comments on Point:Counterpoint: 
Hypobaric hypoxia induces/does not induce different responses from normobaric hypoxia. J Appl Physiol (1985) 112, 1788-1794.

Glenet, S.N., De Bisschop, C., Vargas, F., Guenard, H.J., 2007. Deciphering the nitric oxide to carbon monoxide lung transfer ratio: physiological implications. J Physiol 582, 767-775.

Hackett, P.H., Rennie, D., Levine, H.D., 1976. The incidence, importance, and prophylaxis of acute mountain sickness. Lancet 2, 1149-1155.

Hughes, J.M., van der Lee, I., 2013. The TL,NO/TL,CO ratio in pulmonary function test interpretation. Eur Respir J 41, 453-461.

Ikomi, F., Kawai, Y., Ohhashi, T., 1991. Beta-1 and beta-2 adrenoceptors mediate smooth muscle relaxation in bovine isolated mesenteric lymphatics. J Pharmacol Exp Ther 259, 365-370.

Jambrik, Z., Gargani, L., Adamicza, A., Kaszaki, J., Varga, A., Forster, T., Boros, M., Picano, E., 2010. B-lines quantify the lung water content: a lung ultrasound versus lung gravimetry study in acute lung injury. Ultrasound Med Biol 36, 2004-2010.

Jambrik, Z., Monti, S., Coppola, V., Agricola, E., Mottola, G., Miniati, M., Picano, E., 2004. Usefulness of ultrasound lung comets as a nonradiologic sign of extravascular lung water. Am J Cardiol 93, 1265-1270.

Levine, B.D., Kubo, K., Kobayashi, T., Fukushima, M., Shibamoto, T., Ueda, G., 1988. Role of barometric pressure in pulmonary fluid balance and oxygen transport. J Appl Physiol (1985) 64, 419-428.

Macintyre, N., Crapo, R.O., Viegi, G., Johnson, D.C., van der Grinten, C.P., Brusasco, V., Burgos, F., Casaburi, R., Coates, A., Enright, P., Gustafsson, P., Hankinson, J., Jensen, R., McKay, R., Miller, M.R., Navajas, D., Pedersen, O.F., Pellegrino, R., Wanger, J., 2005. Standardisation of the single-breath determination of carbon monoxide uptake in the lung. Eur Respir J 26, 720-735.

Maggiorini, M., Buhler, B., Walter, M., Oelz, O., 1990. Prevalence of acute mountain sickness in the Swiss Alps. BMJ 301, 853-855.

Maggiorini, M., Melot, C., Pierre, S., Pfeiffer, F., Greve, I., Sartori, C., Lepori, M., Hauser, M., Scherrer, U., Naeije, R., 2001. High-altitude pulmonary edema is initially caused by an increase in capillary pressure. Circulation 103, 2078-2083.

Mahe, L., Chapelain, B., Gargouil, Y.M., Neliat, G., 1991. Characterization of beta-adrenoceptor subtypes and indications for two cell populations in isolated bovine mesenteric lymphatic vessels. Eur J Pharmacol 199, 19-25.

Matthay, M.A., Folkesson, H.G., Clerici, C., 2002. Lung epithelial fluid transport and the resolution of pulmonary edema. Physiol Rev 82, 569-600.

Miller, M.R., Hankinson, J., Brusasco, V., Burgos, F., Casaburi, R., Coates, A., Crapo, R., Enright, P., van der Grinten, C.P., Gustafsson, P., Jensen, R., Johnson, D.C., MacIntyre, N., McKay, R., Navajas, D., Pedersen, O.F., Pellegrino, R., Viegi, G., Wanger, J., Force, A.E.T., 2005. Standardisation of spirometry. Eur Respir J 26, 319-338.

Mutlu, G.M., Koch, W.J., Factor, P., 2004. Alveolar epithelial beta 2-adrenergic receptors: their role in regulation of alveolar active sodium transport. Am J Respir Crit Care Med 170, 1270-1275. 
Naeije, R., Huez, S., Lamotte, M., Retailleau, K., Neupane, S., Abramowicz, D., Faoro, V., 2010. Pulmonary artery pressure limits exercise capacity at high altitude. Eur Respir J 36, 1049-1055.

Pavelescu, A., Faoro, V., Guenard, H., de Bisschop, C., Martinot, J.B., Melot, C., Naeije, R., 2013. Pulmonary vascular reserve and exercise capacity at sea level and at high altitude. High Alt Med Biol 14, 19-26.

Picano, E., Pellikka, P.A., 2016. Ultrasound of extravascular lung water: a new standard for pulmonary congestion. Eur Heart J 37, 2097-2104.

Pratali, L., Cavana, M., Sicari, R., Picano, E., 2010. Frequent subclinical high-altitude pulmonary edema detected by chest sonography as ultrasound lung comets in recreational climbers. Crit Care Med 38, 1818-1823.

Richalet, J.P., 1995. High altitude pulmonary oedema: still a place for controversy? Thorax 50, 923-929.

Roughton, F.J., Forster, R.E., 1957. Relative importance of diffusion and chemical reaction rates in determining rate of exchange of gases in the human lung, with special reference to true diffusing capacity of pulmonary membrane and volume of blood in the lung capillaries. J Appl Physiol 11, 290-302.

Sartori, C., Allemann, Y., Duplain, H., Lepori, M., Egli, M., Lipp, E., Hutter, D., Turini, P., Hugli, O., Cook, S., Nicod, P., Scherrer, U., 2002. Salmeterol for the prevention of high-altitude pulmonary edema. N Engl J Med 346, 1631-1636.

Sartori, C., Rimoldi, S.F., Scherrer, U., 2010. Lung fluid movements in hypoxia. Prog Cardiovasc Dis 52, 493-499.

Snyder, E.M., Beck, K.C., Hulsebus, M.L., Breen, J.F., Hoffman, E.A., Johnson, B.D., 2006. Shortterm hypoxic exposure at rest and during exercise reduces lung water in healthy humans. J Appl Physiol (1985) 101, 1623-1632.

Stewart, G.M., Yamada, A., Haseler, L.J., Kavanagh, J.J., Chan, J., Koerbin, G., Wood, C., Sabapathy, S., 2016. Influence of exercise intensity and duration on functional and biochemical perturbations in the human heart. J Physiol 594, 3031-3044.

Swenson, E.R., 2011. Con: most climbers do not develop subclinical interstitial pulmonary edema. High Alt Med Biol 12, 125-128; discussion 129-130.

Taylor, B.J., Coffman, K.E., Summerfield, D.T., Issa, A.N., Kasak, A.J., Johnson, B.D., 2016. Pulmonary capillary reserve and exercise capacity at high altitude in healthy humans. Eur J Appl Physiol 116, 427-437.

Taylor, B.J., Kjaergaard, J., Snyder, E.M., Olson, T.P., Johnson, B.D., 2011. Pulmonary capillary recruitment in response to hypoxia in healthy humans: a possible role for hypoxic pulmonary venoconstriction? Respir Physiol Neurobiol 177, 98-107.

Wagner, P.D., 1996. A theoretical analysis of factors determining VO2 MAX at sea level and altitude. Respir Physiol 106, 329-343. 
Yock, P.G., Popp, R.L., 1984. Noninvasive estimation of right ventricular systolic pressure by Doppler ultrasound in patients with tricuspid regurgitation. Circulation 70, 657-662.

Zavorsky, G.S., Hsia, C.C., Hughes, J.M., Borland, C.D., Guenard, H., van der Lee, I., Steenbruggen, I., Naeije, R., Cao, J., Dinh-Xuan, A.T., 2017. Standardisation and application of the single-breath determination of nitric oxide uptake in the lung. Eur Respir J 49.

\section{Figure legends}

Figure 1. Group mean \pm SD (panel A) and individual subject (panel B) systolic pulmonary artery pressure (sPAP) at sea-level prior to the expedition (Sea-Level Pre), after 1 day, 5 days and 9 days at Mount Everest Base-camp (EBC Day 1, EBC Day 5 and EBC Day 9), and within 2 weeks of returning back to sea-level after the expedition (Sea-Level Post). $* \mathrm{P}<0.05$, value significantly different vs. Sea-Level Pre-expedition; $† \mathrm{P}<0.05$, value significantly different vs. Sea-Level Postexpedition.

Figure 2. Group mean \pm SD and individual subject lung diffusing capacity for carbon monoxide (DLCO) (panels A and B), alveolar-capillary membrane conductance (Dmco) (panels C and D), and the ratio of Dmco to pulmonary capillary blood volume (Vc) (panels E and F) at sea-level prior to the expedition (Sea-Level Pre), after 1 day, 5 days and 9 days at Mount Everest Base-camp (EBC Day 1, EBC Day 5 and EBC Day 9), and within 2 weeks of returning back to sea-level after the expedition (Sea-Level Post). ${ }^{*} \mathrm{P}<0.05$, value significantly different vs. Sea-Level Pre-expedition; $\dagger \mathrm{P}<0.05$, value significantly different vs. Sea-Level Post-expedition; \#P $<0.05$, value significantly different vs. EBC Day 1.

Figure 3. Group mean \pm SD (panel A) and individual subject (panel B) changes in the number of ultrasound lung comets (ULCs) at sea-level prior to the expedition (Sea-Level Pre), after 1 day, 5 days and 9 days at Mount Everest Base-camp (EBC Day 1, EBC Day 5 and EBC Day 9), and within 2 weeks of returning back to sea-level after the expedition (Sea-Level Post). 

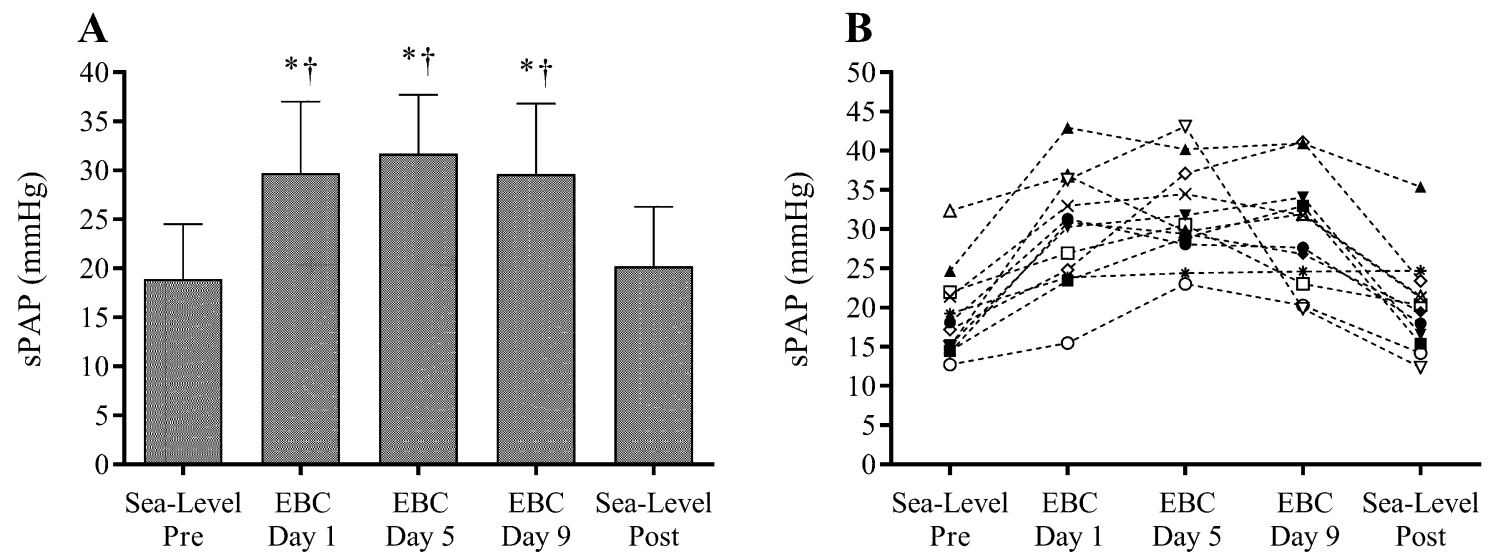

Figure 1. 

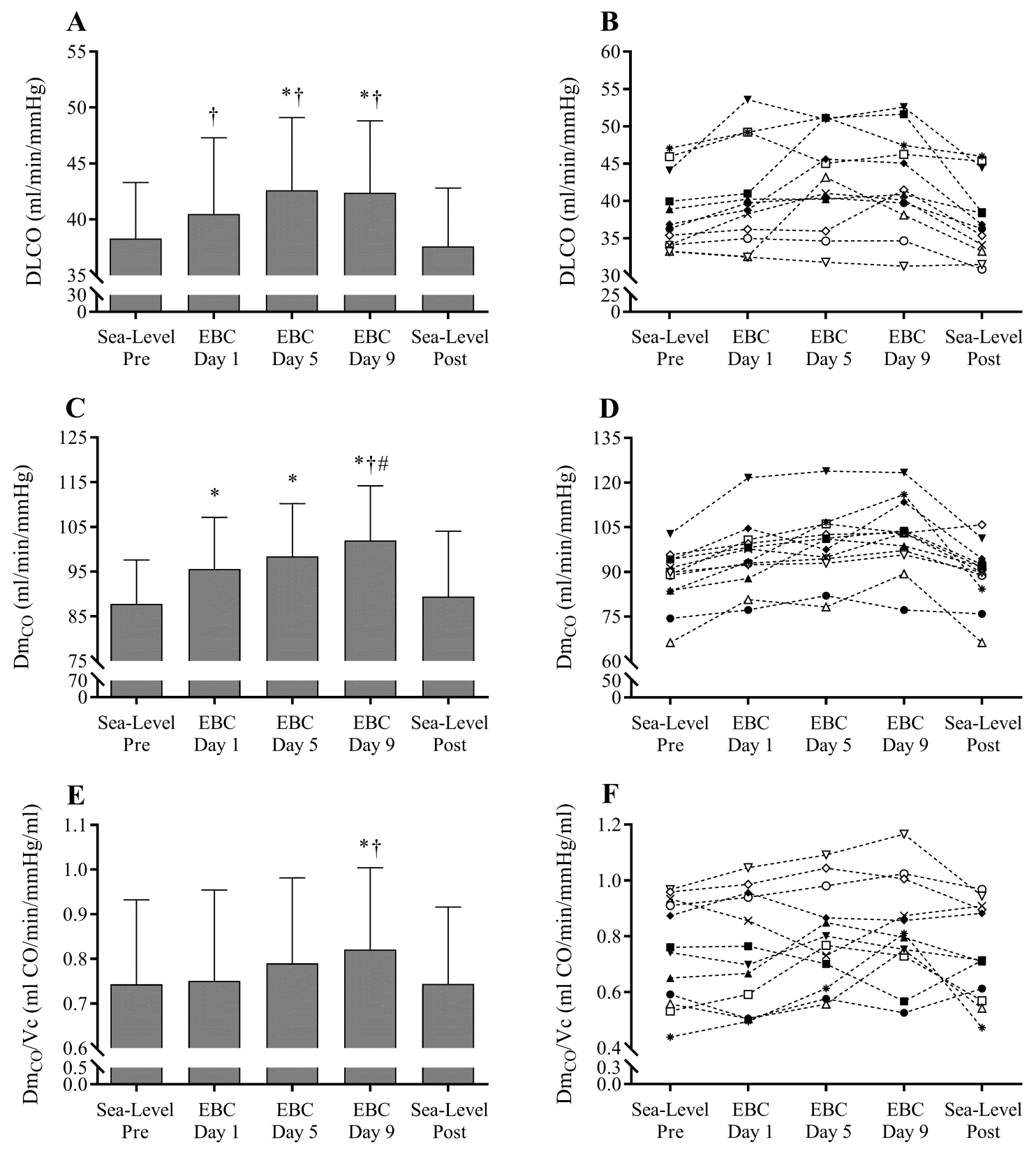

Figure 2. 

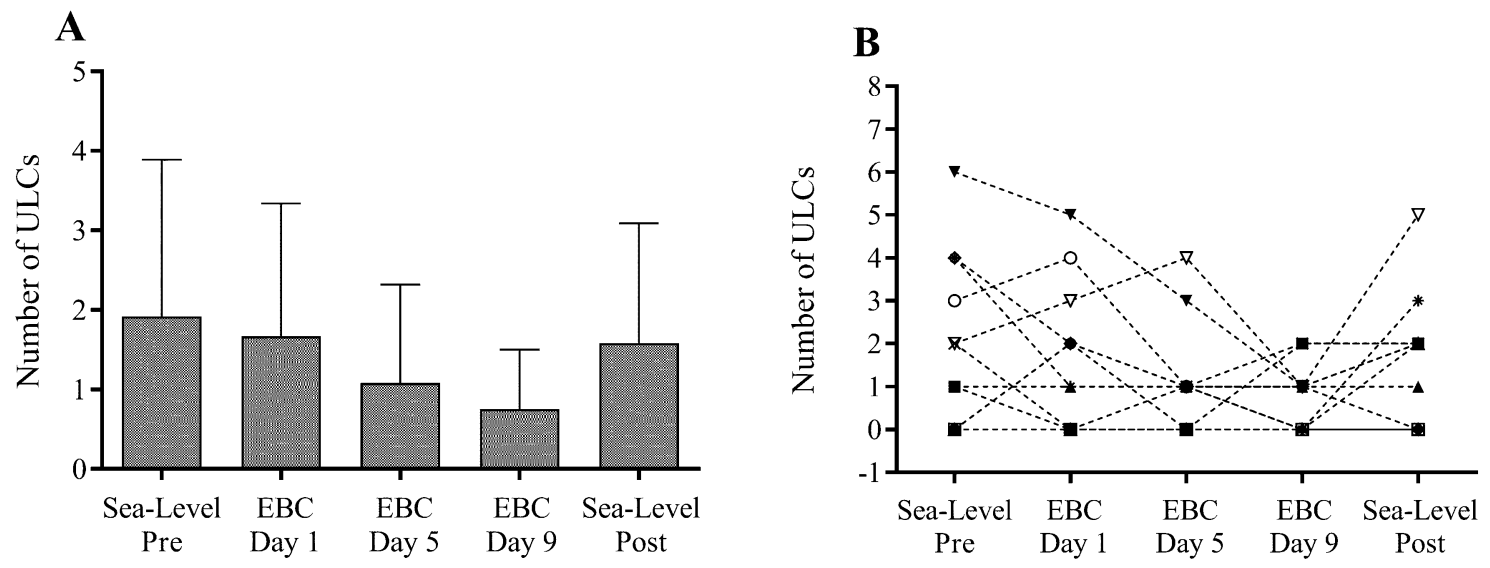

Figure 3. 
Table 1. Effect of high-altitude on Lake Louise score, haemoglobin concentration, arterial oxygen saturation \& resting heart-rate

\begin{tabular}{|c|c|c|c|c|c|c|c|c|c|c|c|c|c|c|c|}
\hline \multirow[b]{2}{*}{ LLS } & \multicolumn{3}{|c|}{$\begin{array}{c}\text { Sea-Level } \\
\text { Pre-expedition } \\
\end{array}$} & \multicolumn{3}{|c|}{$\begin{array}{c}\text { Everest Base-camp } \\
\text { Day } 1 \\
\end{array}$} & \multicolumn{3}{|c|}{$\begin{array}{c}\text { Everest Base-camp } \\
\text { Day } 5 \\
\end{array}$} & \multicolumn{3}{|c|}{$\begin{array}{c}\text { Everest Base-camp } \\
\text { Day } 9 \\
\end{array}$} & \multicolumn{3}{|c|}{$\begin{array}{c}\text { Sea-Level } \\
\text { Post-expedition }\end{array}$} \\
\hline & & - & & 2.1 & \pm & 1.4 & 1.7 & \pm & 1.0 & 1.3 & \pm & 0.9 & & - & \\
\hline$[\mathrm{Hb}], \mathrm{g} / \mathrm{dL}$ & 15.4 & \pm & 1.0 & 17.3 & \pm & $1.1^{* \dagger}$ & 17.4 & \pm & $1.1^{* \dagger}$ & 17.4 & \pm & $1.0^{* \dagger}$ & 15.5 & \pm & 1.0 \\
\hline $\mathrm{SaO}_{2}, \%$ & 97 & \pm & 1 & 82 & \pm & $4^{* \dagger}$ & 84 & \pm & $4^{* \dagger}$ & 85 & \pm & $6^{* \dagger}$ & 98 & \pm & 3 \\
\hline $\mathrm{HR}, \mathrm{bpm}$ & 68 & \pm & 15 & 80 & \pm & $10^{* \dagger}$ & 81 & \pm & $13^{* \dagger}$ & 77 & \pm & $9^{*}$ & 72 & \pm & 12 \\
\hline
\end{tabular}

saturation; $\mathrm{HR}$, resting heart-rate. $* \mathrm{P}<0.05$, value significantly different vs. Sea-Level Pre-expedition; $+\mathrm{P}<0.05$, value significantly different vs. Sea-Level Postexpedition. 
Table 2. Lung function variables at sea-level (before and after the expedition) and at high-altitude

\begin{tabular}{|c|c|c|c|c|c|c|c|c|c|c|c|c|c|c|c|}
\hline \multirow[b]{2}{*}{ FVC, L } & \multicolumn{3}{|c|}{$\begin{array}{c}\text { Sea-Level } \\
\text { Pre-expedition }\end{array}$} & \multicolumn{3}{|c|}{$\begin{array}{c}\text { Everest Base-camp } \\
\text { Day } 1 \\
\end{array}$} & \multicolumn{3}{|c|}{$\begin{array}{c}\text { Everest Base-camp } \\
\text { Day } 5 \\
\end{array}$} & \multicolumn{3}{|c|}{$\begin{array}{c}\text { Everest Base-camp } \\
\text { Day } 9 \\
\end{array}$} & \multicolumn{3}{|c|}{$\begin{array}{c}\text { Sea-Level } \\
\text { Post-expedition }\end{array}$} \\
\hline & 5.72 & \pm & 0.72 & 5.72 & \pm & 0.68 & 5.75 & \pm & 0.68 & 5.74 & \pm & 0.75 & 5.63 & \pm & 0.84 \\
\hline $\mathrm{FEV}_{1} / \mathrm{FVC}, \%$ & 77.0 & \pm & 6.5 & 78.2 & \pm & 6.5 & 78.9 & \pm & 7.0 & 79.0 & \pm & 6.3 & 78.7 & \pm & 6.2 \\
\hline $\mathrm{MEF}_{25-75 \%, \mathrm{~L} / \mathrm{s}}$ & 4.40 & \pm & 0.66 & 4.74 & \pm & 0.82 & 4.82 & \pm & $0.85^{* \dagger \#}$ & 4.91 & \pm & $0.59^{*}$ & 4.45 & \pm & 0.82 \\
\hline
\end{tabular}

Values are group means \pm SD for 12 subjects ( 2 female). FVC, forced vital capacity; $\mathrm{FEV}_{1}$, forced expiratory volume in $1 \mathrm{~s}$; $\mathrm{MEF}_{25-75 \%}$, maximum midexpiratory flow. $* \mathrm{P}<0.05$, value significantly different vs. Sea-Level Pre-expedition; $\uparrow \mathrm{P}<0.05$, value significantly different vs. Sea-Level Post-expedition; \#P < 0.05 , value significantly different vs. Everest Base-camp Day 1. 
Table 3. Heart-rate variability parameters during spontaneous and paced breathing at sea-level (before and after the expedition) and at high-altitude

\begin{tabular}{|c|c|c|c|c|c|c|c|c|c|c|c|c|c|c|c|}
\hline \multirow{2}{*}{$\mathrm{SDNN}, \mathrm{ms}$} & \multicolumn{3}{|c|}{$\begin{array}{c}\text { Sea-Level } \\
\text { Pre-expedition }\end{array}$} & \multicolumn{3}{|c|}{$\begin{array}{c}\text { Everest Base-camp } \\
\text { Day } 1\end{array}$} & \multicolumn{3}{|c|}{$\begin{array}{c}\text { Everest Base-camp } \\
\text { Day } 5 \\
\end{array}$} & \multicolumn{3}{|c|}{$\begin{array}{c}\text { Everest Base-camp } \\
\text { Day } 9\end{array}$} & \multicolumn{3}{|c|}{$\begin{array}{c}\text { Sea-Level } \\
\text { Post-expedition } \\
\end{array}$} \\
\hline & \multicolumn{15}{|c|}{ Spontaneous breathing } \\
\hline \multirow[t]{2}{*}{ RMSSD, ms } & 67.5 & \pm & 22.0 & 64.1 & \pm & 19.0 & 67.2 & \pm & 14.6 & 58.2 & \pm & 17.7 & 73.9 & \pm & 31.1 \\
\hline & \multicolumn{15}{|c|}{ Paced breathing ( 6 breaths/min) } \\
\hline RMSSD, ms & 100.4 & \pm & 31.6 & 94.5 & \pm & 26.4 & 82.4 & \pm & 23.9 & 82.1 & \pm & 29.5 & 81.0 & \pm & $29.1^{*}$ \\
\hline
\end{tabular}

